International Journal of Power Electronics and Drive System (IJPEDS)

Vol. 11, No. 4, December 2020, pp. 1918 1925

ISSN: 2088-8694, DOI: 10.11591/ijpeds.v11.i4.pp1918-1925

1918

\title{
Evaluation of DC-DC converter using renewable energy sources
}

\author{
Rajapandian B., G.T. Sundarrajan
}

Department of Electrical and Electronics Engineering, Sathyabama Institute of Science and Technology, India

\begin{tabular}{l} 
Article Info \\
\hline Article history: \\
Received Dec 19, 2019 \\
Revised Feb 4, 2020 \\
Accepted Jul 29, 2020 \\
\hline Keywords: \\
Advnaced semiconductor \\
devices \\
Harmonics \\
Renewable Energy \\
SEPIC Converter \\
Switching elemen \\
Total Harmonic Distortion \\
Wind Energy \\
\hline
\end{tabular}

\begin{abstract}
This work analyses and evaluates the performance of renewable energy sources-based converters using Intelligent techniques. The objective of the research is to maintain the reliability of the converters such that it decreases the switching losses, high duty cycle and recycles the leakage energy. To accomplish the high output voltage gain converters are designed with different intelligent methods. Due to heavy demands, the cost of fossil fuel has gone up.so the need for the time is identifying and developing renewable energy sources along with developing new technologies for energy saving in renewable energy system to fight the issues plaguing the environment.
\end{abstract}

This is an open access article under the CC BY-SA license.

\section{Corresponding Author:}

Rajapandian B,

Department of Electrical and Electronics Engineering,

Sathyabama Institute of Science and Technology,

Chennai, Tamilnadu, India

Email: rajeee.pandian46@gmail.com

\section{INTRODUCTION}

Owing to features such as zero carbon footprint, enormous energy generation potential, being renewable and sustainable in nature, wind energy augurs well to be the most promising source of sustainable energy with immense futuristic scope. The great extent of technological enhancement has seen multi Mega Watt of energy being produced in a single wind turbine system from a mere few tens of kilowatts of power being produced in 1980's. Factors such as air density and wind velocity plays a vital role in harnessing energy from wind and Numerous intelligent techniques based wind energy system have been presented in literature[1].Owing to the wind speed's stochastic nature ,the deterministic reliability prediction methods which are conventionally used in Industrial application is not a viable option for wind turbine applications. These algorithms despite being robust and intelligent as assumed by authors in [3] are used in applications that allows only a minimum variation in wind speed and also requires a constant air density assumption which the authors in [2] have assumed.

The model has various inherent advantages such as reduced simulation time, eliminates the negative aspects associated with pulse width modulation switching and also reduces the thermal stress by employing the controller tuning methodology. The paper presents an overall perspective of the SEPIC based wind energy conversion system and gives an insight into the frame work of evaluation of the converters.

Distributed wind generation units like DFIG makes use of the positives in the converters and the various modes of control being made use of at the point of common coupling for supporting the grid with additional reactive power. The DG interconnection with the distribution network makes use of IEEE 1547 standards and based on them, DGs need to have a constant PF close to unity at PCC and to achieve it multiple switched capacitor bank support is required. [4]. Despite active voltage regulation is 
prohibited by these standards to a certain extent, voltage regulation can be performed if there is a consensus amongst DG owners and the utility providers [5]. The size of the DG will decide whether to operate it in power factor control mode, voltage control mode or voltage regulation mode [6]. Of late Power factor control mode is used for controlling the smaller units while voltage control mode suits the larger DG units provided, the power factor being maintained at unity PCC in terms of reducing the THD value [7] in the power factor control mode by modeling it as a PQ bus with negative current injections[8].

\section{RESEARCH METHOD}

Figure 1 shows the block diagram of wind energy system used. Generator is very difficult to connect with grid directly, Converter is an interface between that two sections [9]. DFIG being a variable speed generator possess a distinct advantage over the fixed speed generators with regards to its variable speed capability. Reduced power conversion paves the way for reduced losses, improved efficiency, enhanced power factor and in turn provides reactive power to the grid [10]. The necessity of a gearbox in order to increase speed coupled with the wind turbine - generator combination is the basic draw back in the case of DFIG while the PMSG in order to achieve direct drive control is machined with sufficient number of poles in accordance with the requirement [11].

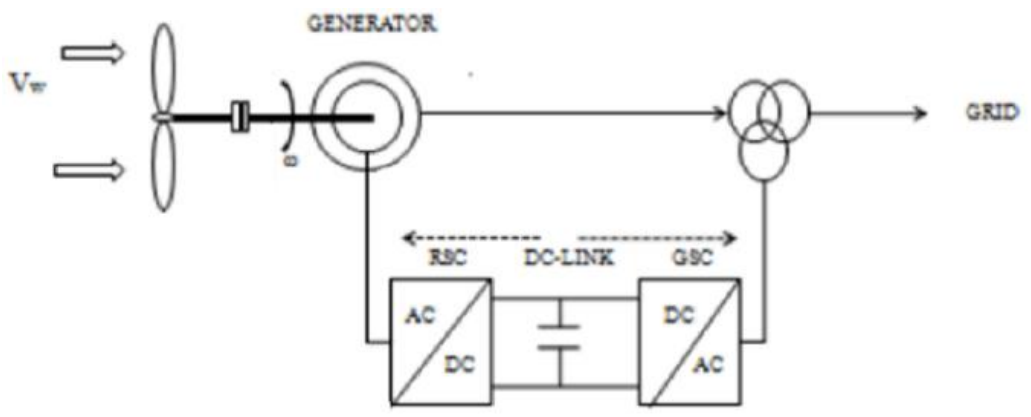

Figure 1. Block diagram of wind energy system

\section{PROPOSED SYSTEM}

In the proposed system converter performance has been enhanced by means of reducing their power consumption, reduced switching and power losses [12]. Here the Total Harmonic Distortion (THD) values were reduced to the prescribed limit in terms of inserting the LC filter along with the required output. Both the values of direct $\mathrm{AC}$ and converted $\mathrm{AC}$ have been compared and their THD values are calculated [13]. In order to achieve lower voltage level with regards to the DC-DC converter the synchronous converter stands out as a perfect option due to the lower conduction loss in the diode [14]. The soft switching technique is employed in the high side MOSFET so that the switching losses are eliminated. In addition to that the resonant secondary circuit is designed to avoid the switching losses [15]. This method as suggested above accomplishes an efficient convertion by employing an advanced design technique and in this regard the converter performance has been analyzed [16].

\section{MODES OF OPERATION}

\subsection{Mode I: DC-AC converterd input}

A power converter generally employed for conversion of electrical energys being an electrical or electro mechanical device could be constructed as a simple transformer to convert the voltage of AC power or it can also be made into a complex system [17]. This is the technical term which refers to a class of electrical machine which is used in accomplishing the conversion from one frequency component of alternating current in to another frequency component [18]. DC supply is converted in to AC by means of rectification and then it is fed to the converter[19].Owing to the voltage step-up/step-down capability a SEPIC Converter is used for the wind energy system as well as its un-inverted output(as distinguished by conventional buck-boost converter)[20].Output Voltage has been obtained and its THD value also been determined.Figure 2 displays the simulated DC-AC Converted input [21]. 


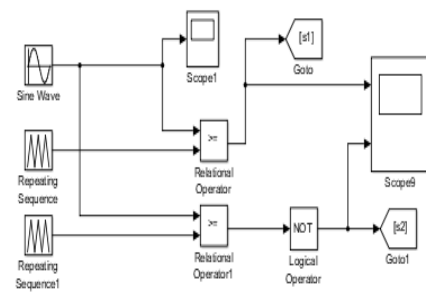

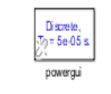

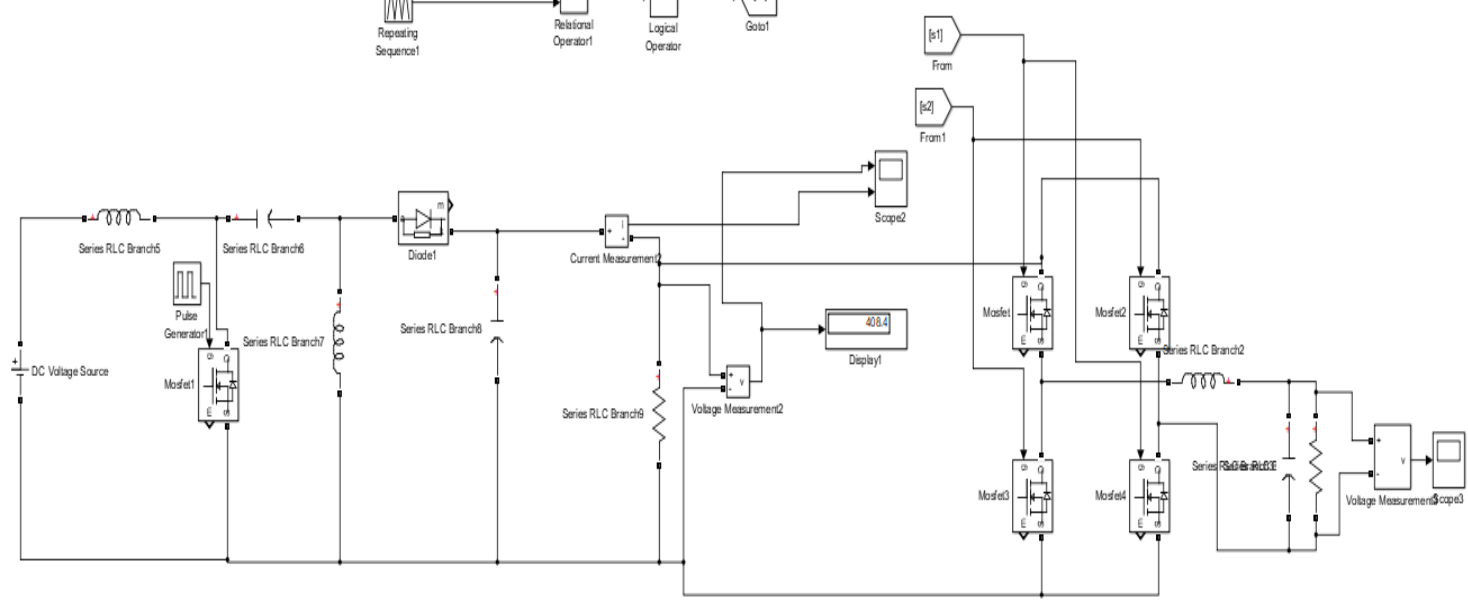

Figure 2. Simulation diagram of DC-AC converted Input

\subsection{Mode II: Direct ac input}

Electrical drives for direct drive renewable energy systems, but the most important process of high frequency switching results in negative effects [22]. Here a rectifier is often included to convert the AC power in the mains, galvanic isolation between the input and output modules of converter [23]. AC voltage is directly fed to the converter section [24]. Here also output voltage has been obtained with their relevant THD values. Figure 3 shows the simulation diagram of direct AC input [25]. In this mode, supply from wind energy is directly fed to the converter to reduce the losses when used to apply the direct ac input [26].

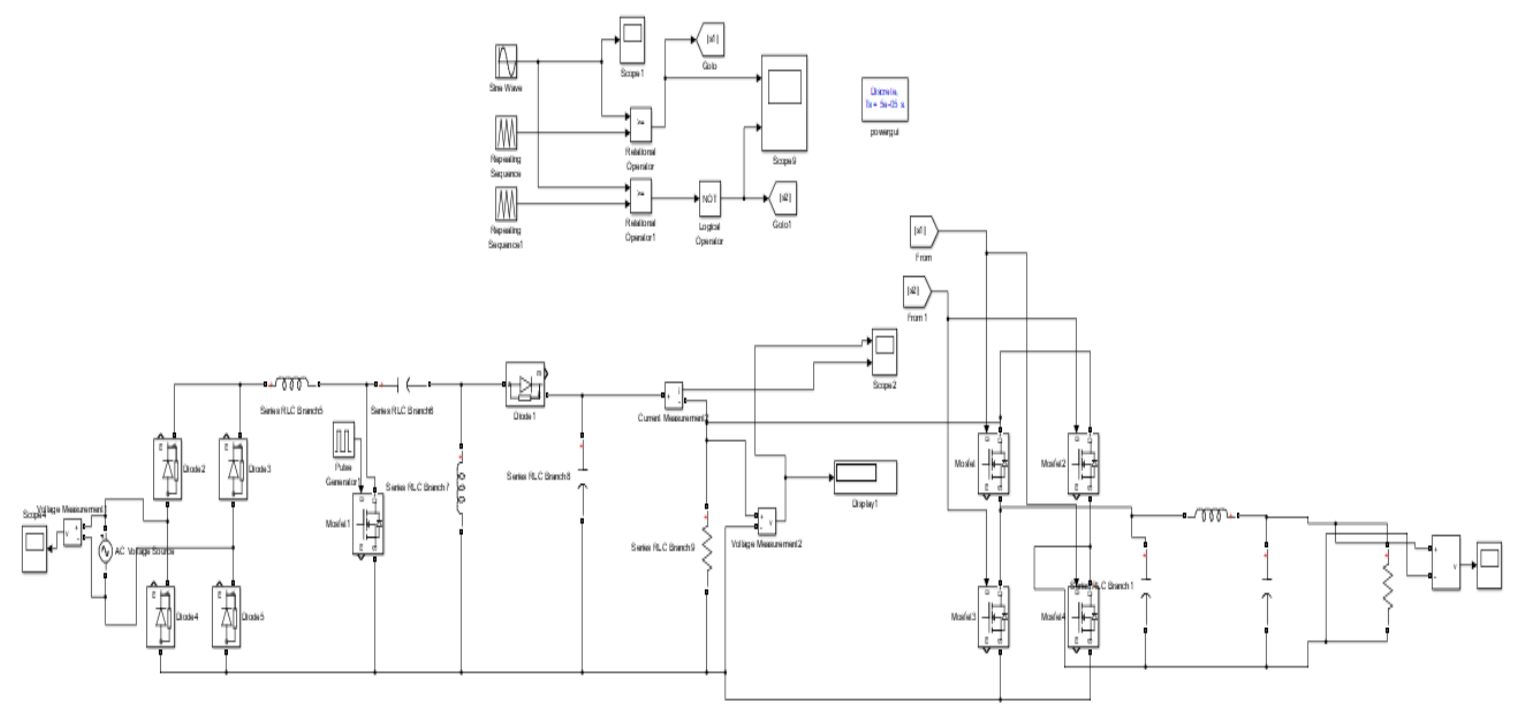

Figure 3. Simualtion diagram of Direct AC Input

\section{RESULTS AND DISCUSSIONS}

Figure 5 shows the Input voltage waveform of giving inverted DC supply. Ripple contents are eliminated interms of providing filter and the converted $\mathrm{AC}$ is apllied to the switching circuit. 
Figure 6 shows the outpiut voltage waveform of the same case which is to be in the form of sinusoidal signal,the harmonics contents are eliminated by means of providing filter in the output side,the THD values are considerably reduced in the application of filter which is mentioned in the table.1.By means of evaluating the converter performance the THD value can be concluded in to the permissible limit as well as switching losses and heating effect can also be reduced in this performance configuration.

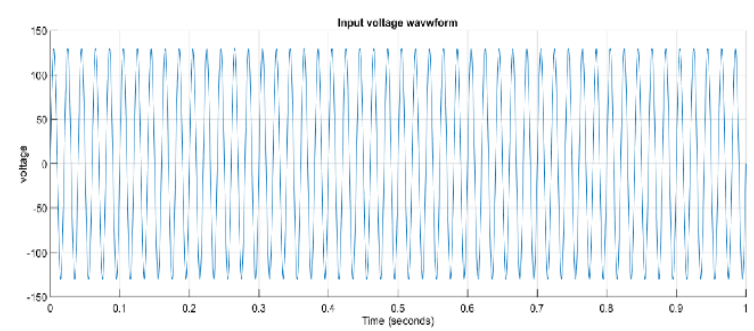

Figure 5. DC-AC converted input voltage

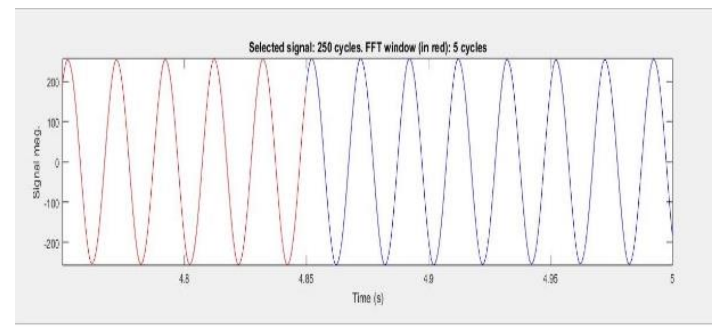

Figure 6. output voltage waveform

Table 1 Shows the thd values of output voltage of conversion of DC to ac input for various range of frequencies.THD value can be reduced in the permissible limit.

Table 1. THD values for different frequencies

\begin{tabular}{llll}
\hline Frequency $(\mathrm{Hz})$ & Component & THD $(\%)$ & Angle(degree $)$ \\
\hline 0 & (DC) & 0.10 & 270.0 \\
10 & & 0.11 & -31.9 \\
20 & & 0.14 & -66.0 \\
30 & & 0.20 & -80.8 \\
40 & & 0.26 & 249.2 \\
50 & (Fun) & 100.00 & 49.6 \\
60 & & 0.38 & 114.8 \\
70 & & 0.13 & 79.3 \\
80 & & 0.06 & 69.0 \\
90 & & 0.00 & 97.7 \\
100 & (h2) & 0.05 & 114.9 \\
110 & & 0.04 & 106.2 \\
120 & & 0.03 & 99.3 \\
130 & & 0.03 & 107.6 \\
140 & & 0.02 & 63.8 \\
150 & (h3) & 0.06 & 68.6 \\
160 & & 0.02 & 68.9 \\
170 & & 0.01 & 66.0 \\
180 & & 0.01 & 120.7 \\
190 & & 0.01 & -86.8 \\
200 & (h4) & 0.00 & 74.8 \\
220 & & 0.01 & 85.5 \\
230 & & 0.01 & 84.3 \\
240 & & 0.01 & -30.6 \\
250 & & 0.01 & 29.3 \\
260 & (h5) & 0.33 & 37.0 \\
270 & & 0.00 & 62.7 \\
280 & & 0.00 & 37.0 \\
\hline & & 0.00 & 52.7 \\
\hline
\end{tabular}

\section{FFT ANALYSIS}

Sampling Time: $5 \mathrm{e}-06 \mathrm{~S}$

Fundamental:254.9(180.3rms)

DC component: 0.2555

THD: 0.814

Figure 7 shows the input voltage waveform when applying direct DC supply. Figure 8 and Figure 9 shows the input cuurent and output voltage waveform of applying direct DC suppy, here LC filter is used to reduce the harmonics in the output side.Due to the filter concentration THD values are reduced in to the level. 


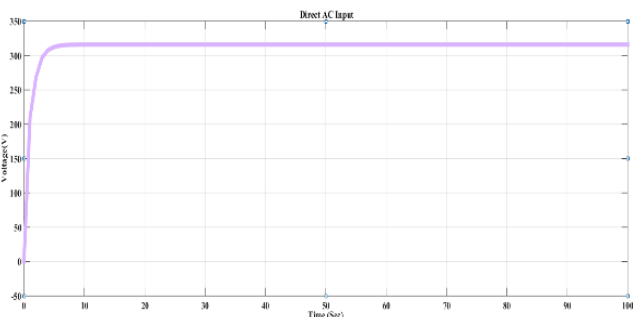

Figure 7. Input voltage of direct AC

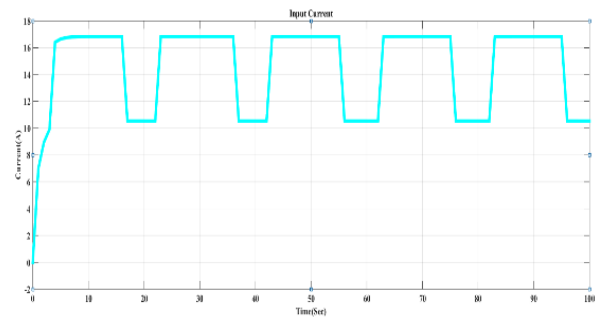

Figure 8. Input current of direct AC

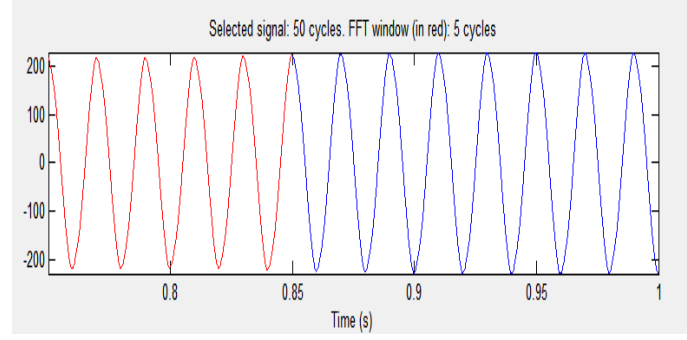

Figure 9. Output voltage waveform

Table 2 shows the THD values of output voltage of conversion of direct AC input for various range of frequencies.THD values are reduced in the advisable level.

Table.2 THD Values For Different Frequencies

\begin{tabular}{cccc}
\hline Frequency-Hz & Component & THD $(\%)$ & Angle(degree) \\
\hline 0 & (DC) & 0.10 & 270.0 \\
10 & & 0.11 & -31.9 \\
20 & & 0.14 & -64.0 \\
30 & & 0.20 & -80.8 \\
40 & & 0.26 & 249.2 \\
50 & (Fun) & 100.00 & 49.6 \\
60 & & 0.38 & 114.8 \\
70 & & 0.13 & 79.3 \\
80 & & 0.06 & 69.0 \\
90 & & 0.00 & 97.7 \\
100 & (h2) & 0.05 & 114.9 \\
110 & & 0.04 & 106.2 \\
120 & & 0.03 & 99.3 \\
130 & & 0.03 & 107.6 \\
140 & & 0.02 & 63.8 \\
150 & (h3) & 0.06 & 68.6 \\
160 & & 0.02 & 68.9 \\
170 & & 0.01 & 66.0 \\
180 & & 0.01 & 120.7 \\
190 & & 0.01 & -86.8 \\
200 & (h4) & 0.00 & 74.8 \\
210 & & 0.01 & 85.5 \\
220 & & 0.01 & 84.3 \\
230 & & 0.01 & -30.6 \\
240 & & 0.01 & 29.3 \\
250 & (h5) & 0.33 & 37.0 \\
260 & & 0.00 & 62.7 \\
270 & & 0.00 & 37.0 \\
280 & & 0.00 & 52.7 \\
\hline
\end{tabular}

\section{FFT ANALYSIS}

Sampling Time: 5e-06S

Sample per cycles:400

DC component:0.2555

Fundamental:254.9(180.3rms)

THD: 0.814 
Figure 10 and Figure 11 shows the input voltage and input current waveform of direct wind and Figure 12 shows the output voltage waveform when applying direct supply from direct wind energy. Table. 3 shows the comparison value of Voltage and THD value of above three modes of operation. THD value is almost same for direct $\mathrm{AC}$ input and Wind input

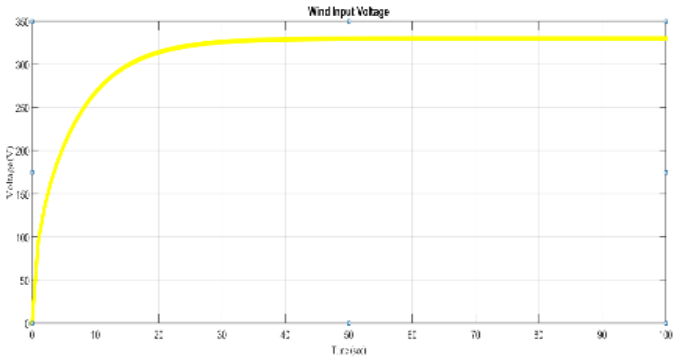

Figure 10. input voltage of direct wind

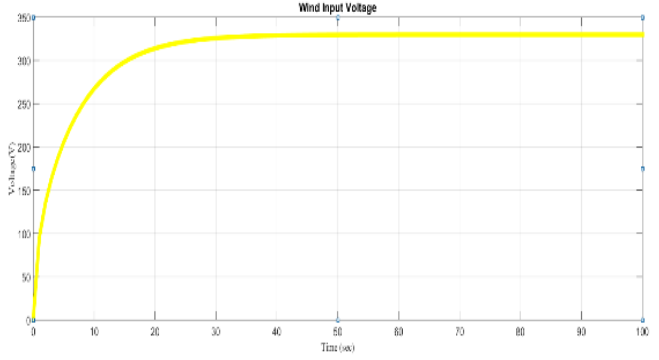

Figure 11. input current of direct wind

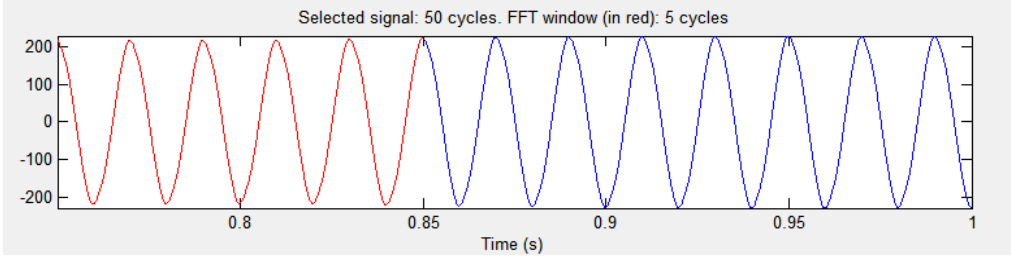

Figure 12. Output Voltage Waveform

Table 3. comparison value of Voltage and THD

\begin{tabular}{lll}
\hline Category & Output voltage(volts) & THD (\%) \\
\hline $\begin{array}{l}\text { DC-AC converted } \\
\text { input }\end{array}$ & 230 & 0.814 \\
$\begin{array}{l}\text { Direct AC input } \\
\text { from wind }\end{array}$ & 200 & 2.74 \\
\hline
\end{tabular}

\section{CONCLUSION}

Converter has the ability to work form an supply voltage which is greater or less than the regulated output voltage. Converter design which includes minimal active elements, a simple controller and relevant waveforms which provide low noise operation. Harmonics in the power systems result in increased heating in the equipment and conductors, thus resulting in misfiring of variable speed drives and torque variations in motors. Total harmonics distortion is a complex and often confusing concept to understand. From the above analysis it can be concluded that the converter performance has been enhanced as well as the total harmonic distortion has been reduced to a considerable level. By means of reducing the THD value, the entire working of converter with the wind energy input has been improved to a considerable level and this paper also proves that the lower range of THD in Power systems paves the way for high power factor, low peak currents and higher efficiency. Simulation results prove that the output voltage is controlled as per the requirements and it changes by controlling the duty cycle.

\section{REFERENCES}

[1] A. Gopi, R. Saravanakumar, "High step-up isolated efficient single switch DC-DC converter for renewable energy source," Ain shams engineering journal, Vol. 5, No. 4, pp. 1115-1127, June 2014

[2] Josephine Rathinadurai Louis, Suja Shan mugham, Jovitha Jerome, "Encompassing nine switch converter approach in wind-hydro hybrid power system feeding three phase three wire dynamic loads," International Journal of Electrical Power \& Energy Systems, Vol. 79, pp. 66-74, 2016.

[3] E. Durán, J.M. Andújar, F. Segura, A.J. Barragán, "A high-flexibility DC load for fuel cell and solar arrays power sources based on DC-DC converters," Applied energy, vol. 88, no 5, pp. 1690-1702, 2010.

[4] R.Hemaprithini and G.T.Sundarrajn, "Three level Integrated AC to DC Converter fed DC drive with cascaded filter," International Journal of Applied Engineering Research,Vol 10,No. 6, pp.5140-5146, 2015. 
[5] G.T.Sundar Rajan, "Power Quality Improvement at Input and Output stages of three pahse diode rectifier using Artificial intelligent techniques for DC and AC drive Apllications," IEEE International conference on Computational Intelligence and Computing Research(ICCIC-2014), 2014.

[6] G.T.Sundar Rajan and C.Christoberv Asir Rajan, "Input stage improved power factor of the three phase diode rectifier using hybrid unidirectional rectifier," International Conference on Nanoscience,Engineering and technology-ICONSET-2011. November 28 to 30, pp. 697 - 682, 2011.

[7] Suganya, R., Kamaraj, N., \& Sudalaimani, M. "Reduction of THD in Single Phase AC to DC Boost Converter using PID controller," 2014 IEEE International Conference on Advanced Communications, Control and Computing Technologies, pp. 147-151, 2014.

[8] George ML, Abirami P. "THD analysis between 5LT2C and 7LT2C inverter," 2017 International Conference on Computation of Power, Energy Information and Commuincation (ICCPEIC), pp. 672-676, 2017.

[9] Rajapandian. B, Harini. V, Raksha. D, Sangeetha. V, "A Novel Approach as an AID for blind, deaf and dump people," $3^{\text {rd }}$ IEEE International Conference on Sensing, Signal Processing and Security, ICSSS, 2017.

[10] Rajapandian. B, Madhanamohan. K, Tamilselvi. T, Prithiga. R, "Smart dustbin," International Journal of Engineering and Advanced Technology, Vol. 8, No. 6, pp. 4790-4795, 2019.

[11] Tamilselvi. T, Kayalvizhi. K, Rajapandian. B, Nithyarani. N, "A research on electronic component wrecker using electro-magnet pulse (EMP)," International Journal of Engineering and Advanced Technology, Vol. 8, No. 6, pp. 3641- 3645, 2019.

[12] T. McRae and A. Prodić, "Design Oriented Analysis of Switched Capacitor DC-DC Converters," IEEE Open Journal of Power Electronics, vol. 1, pp. 2-13, 2020.

[13] Oscar Yu, Cheng-Wei Chen, Chih-Shen Yeh, Jih-Sheng Lai, "Drain-Source Synchronous Rectifier Oscillation Mitigation in Light-Load Conditions," IEEE Open Journal of Power Electronics, pp. 14-23, 2019.

[14] Y. Li and Y. W. Li, "Power Converters Topological Transformation Using Dual and Isomorphic Principles," IEEE Open Journal of Power Electronics, vol. 1, pp. 74-87, 2020.

[15] S. Peyghami, P. Palensky and F. Blaabjerg, "An Overview on the Reliability of Modern Power Electronic Based Power Systems," IEEE Open Journal of Power Electronics, vol. 1, pp. 34-50, 2020

[16] M. G. Taul, X. Wang, P. Davari and F. Blaabjerg, "Current Limiting Control with Enhanced Dynamics of GridForming Converters During Fault Conditions," IEEE Journal of Emerging and Selected Topics in Power Electronics, vol. 8, no. 2, pp. 1062-1073, June 2020

[17] Blaabjerg F, Ma K. "Future on power electronics for wind turbine systems," IEEE Journal of emerging and selected topics in power electronics. Vol. 1, no. 3, pp. 139-52, 2013.

[18] T. M. Jahns and H. Dai, "The past, present, and future of power electronics integration technology in motor drives," CPSS Transactions on Power Electronics and Applications, vol. 2, no. 3, pp. 197-216, Sept. 2017

[19] M. Antivachis, J. A. Anderson, D. Bortis and J. W. Kolar, "Analysis of a synergetically controlled two-stage three-phase DC/AC buck-boost converter," in CPSS Transactions on Power Electronics and Applications, vol. 5, no. 1, pp. 34-53, March 2020

[20] P. Jia and Y. Yuan, "Analysis and design of an isolated high step-up converter based on the secondary side quasiresonant loops," in IET Power Electronics, vol. 13, no. 6, pp. 1129-1143, 652020

[21] E. Rahmanian, H. Akbari and G. H. Sheisi, "Maximum Power Point Tracking in Grid Connected Wind Plant by Using Intelligent Controller and Switched Reluctance Generator," in IEEE Transactions on Sustainable Energy, vol. 8, no. 3, pp. 1313-1320, July 2017

[22] U. K. Kalla, B. Singh and S. S. Murthy, "Intelligent Neural Network-Based Controller for Single-Phase Wind Energy Conversion System Using Two Winding Self-Excited Induction Generator," in IEEE Transactions on Industrial Informatics, vol. 12, no. 6, pp. 1986-1997, Dec. 2016

[23] T. K. Mahmoud, Z. Y. Dong and J. Ma, "A Developed Integrated Scheme Based Approach for Wind Turbine Intelligent Control," in IEEE Transactions on Sustainable Energy, vol. 8, no. 3, pp. 927-937, July 2017.

[24] C. Bou-Mosleh, P. Rahme, P. Beaino, R. Mattar and E. A. Nassif, "Contribution to clean energy production using a novel wave energy converter: Renewable energy," International Conference on Renewable Energies for Developing Countries 2014, Beirut, 2014, pp. 108-111.

[25] K. Anoune, M. Bouya, M. Ghazouani, A. Astito and A. B. Abdellah, "Hybrid renewable energy system to maximize the electrical power production," 2016 International Renewable and Sustainable Energy Conference (IRSEC), Marrakech, 2016, pp. 533-539

[26] K. Kajiwara, T. Kazuki, S. Ikeda, N. Matsui and F. Kurokawa, "Performance Mechanism of Active Clamp Resonant SEPIC Converter in Renewable Energy Systems," 2019 8th International Conference on Renewable Energy Research and Applications (ICRERA), Brasov, Romania, 2019, pp. 1042-1046 


\section{BIOGRAPHIES OF AUTHORS}
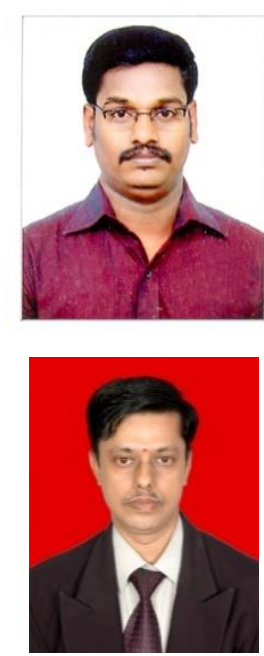

B.Rajapandian, born in Pudukkottai District, Tamilnadu State, India in1982,received B.E degree in Electrical and Electronics from the Madurai Kamaraj University and the M.E degree in Power Electronics and Industrial Drives in Sathyabama University, Chennai, India in 2003,2007 respectively and the Research Scholar of Sathyabama Institute Of Science and Technology,Chennai,Tamilnadu.He has published technical papers in International, National Journal and Conferences .Presently he is working as a Associate Professor in the Department of EIE at Sri Sairam Engineering College,Chennai. He has the total teaching experience of 14 years. His areas of interest are Power Electronics, Power Quality, Non-conventional energy sources, AC and DC drives.

G. T. SUNDAR RAJAN has B.E in madras university and M.E in Sathyabam university. He has 18 years of experience in teaching and one year in industry. His main research area in power electronics are modelling of DC and ac drives. He has published technical papers in international and national journals and conferences. Presently he is working as an Associate Professor in the Department of EEE at Sathyabama Institute of Science and Technology, Chennai. 